\title{
Article \\ Determination of Tetracycline, Oxytetracycline, Sulfadiazine, Norfloxacin, and Enrofloxacin in Swine Manure Using a Coupled Method of On-Line Solid-Phase Extraction with the UHPLC-DAD
}

\author{
Mohamed S. Gaballah 1,2 (D), Xin Li ${ }^{1}$, Zijia Zhang ${ }^{1}$, Abdulaziz Al-Anazi ${ }^{3}$, Hui Sun ${ }^{1}$, Mostafa Sobhi ${ }^{4}$, \\ Mperejekumana Philbert ${ }^{1}$, Mohamed A. Ghorab ${ }^{5,6}$, Jianbin Guo ${ }^{1, *}$ and Renjie Dong ${ }^{1,7}$
}

check for updates

Citation: Gaballah, M.S.; Li, X.; Zhang, Z.; Al-Anazi, A.; Sun, H.; Sobhi, M.; Philbert, M.; Ghorab, M.A.; Guo, J.; Dong, R. Determination of Tetracycline, Oxytetracycline, Sulfadiazine, Norfloxacin, and Enrofloxacin in Swine Manure Using a Coupled Method of On-Line Solid-Phase Extraction with the UHPLC-DAD. Antibiotics 2021, 10 , 1397. https://doi.org/10.3390/ antibiotics 10111397

Academic Editor: Carlos M. Franco

Received: 10 October 2021

Accepted: 9 November 2021

Published: 13 November 2021

Publisher's Note: MDPI stays neutral with regard to jurisdictional claims in published maps and institutional affiliations.

Copyright: (c) 2021 by the authors. Licensee MDPI, Basel, Switzerland. This article is an open access article distributed under the terms and conditions of the Creative Commons Attribution (CC BY) license (https:/ / creativecommons.org/licenses/by/ $4.0 /)$.
1 Bioenergy and Environment Science \& Technology Laboratory, College of Engineering, China Agricultural University, Beijing 100083, China; saadga22@gmail.com (M.S.G.); 1xin@cau.edu.cn (X.L.); zijiazhang@cau.edu.cn (Z.Z.); huisun@cau.edu.cn (H.S.); philbertson2@yahoo.com (M.P.); Dong@cau.edu.cn (R.D.)

2 Department of Marine Environment, National Institute of Oceanography and Fisheries, NIOF, Alexandria 21556, Egypt

3 Department of Chemical Engineering, College of Engineering, King Saud University (KSU), P.O. Box 800, Riyadh 11421, Saudi Arabia; aalanazi15@ksu.edu.sa

4 Agricultural and Bio-Systems Engineering Department, Faculty of Agriculture, Alexandria University, Alexandria 21511, Egypt; Msi1433@gmail.com

5 Office of Chemical Safety and Pollution Prevention, U.S. Environmental Protection Agency (EPA), Washington, DC 20004, USA; ghorab.mohamed@epa.gov

6 Wildlife Toxicology Laboratory, Department of Animal Science, Institute for Integrative Toxicology (IIT), Michigan State University, East Lansing, MI 48824, USA

7 Yantai Institute, China Agricultural University, Yantai 264032, China

* Correspondence: jianbinguo@cau.edu.cn

Abstract: The use of various veterinary antibiotics (VAs) in animal husbandry raises serious concerns about the development of antibiotic resistance. Antibiotics such as tetracycline, oxytetracycline, sulfadiazine, norfloxacin, and enrofloxacin are the most frequently used antimicrobial compounds in animal husbandry and generate large eco-toxicological effects; however, they are still difficult to determine in a complex matrix such as swine manure. This study has developed an effective method for detecting five VAs in swine manure using Ultra-High-Performance Liquid ChromatographyDiode Array Detector (UHPLC-DAD) coupled with on-line solid-phase extraction (SPE). The results show that the mobile phase of ACN/0.01 M oxalic acid was the optimum at $\mathrm{pH} 3.0$. VAs in a swine manure matrix were extracted using solid extraction buffer solution (T3) with $97.36 \%$ recovery. Sensitivity, accuracy, and precision were also evaluated. The validity study showed good linearity $\left(\mathrm{R}^{2}>0.99\right.$ ). Limit of detection (LOD) was found to be from 0.1 to $0.42 \mu \mathrm{g} \mathrm{mL}^{-1}$ in the liquid fraction and from 0.032 to $0.58 \mu \mathrm{g} \mathrm{g}^{-1} \mathrm{dw}$ in the solid fraction. The corresponding values of the limit of quantification (LOQ) ranged from 0.32 to $1.27 \mu \mathrm{g} \mathrm{mL} \mathrm{m}^{-1}$ for the liquid fraction and from 0.096 to $1.77 \mu \mathrm{g} \mathrm{g}^{-1} \mathrm{dw}$ for the solid fraction. Therefore, the proposed method showed the potential applicability for detecting different antibiotic compounds from swine manure samples.

Keywords: UHPLC; on-line SPE; swine manure; veterinary antibiotics

\section{Introduction}

Veterinary antibiotics (VAs), including tetracyclines (TCs), sulfonamides (Sulfs), and fluoroquinolones (FQs), are frequently used to promote animal growth and prevent disease in the livestock industry [1,2]. Because of their widespread misuse and difficulty to digest in the animal's gut, a certain amount of VAs is excreted into the animal's feces $[2,3]$. Furthermore, the residues of these VAs are toxic and can cause serious allergic reactions 
in the environment. Animal manure is frequently employed in agriculture, resulting in the introduction of antibiotic resistance genes (ARGs) into the soil system [4]. China is one of the biggest VAs producers worldwide, with tetracycline accounting for half of all VAs produced each year (including antibiotics used in animal feed) [5]. Previous studies have described microbiological and thin-layer chromatography methods for monitoring VAs in biological matrices [6-8]; however, most of those studies have focused on one group of VAs only. Several recent studies used HPLC for TCs, sulfonamides, and FQs quantification in other animals' matrices [9-13].

High-performance liquid chromatography (HPLC) in the reverse-phase mode, with different detection modes, is commonly used to determine VAs. Between them, TCs are frequently investigated; however, they are unstable compounds due to high light sensitivity and the formation of epimers under acidic conditions. TCs in honey were detected using on-line SPE coupled with HPLC by Li et al. [7], and in chicken meat and liver by Shalaby and Yu using HPLC [2]. HPLC was also used to determine FQs in human plasma [14,15] and Sulfs in manure and solid matrices [16]. This implies that TCs, Sulfs, and FQs can be successfully determined using HPLC coupled with different detection modes in various matrices; however, only a few methods have been developed for animal manure samples.

Moreover, most of the procedures involved a complicated extraction step such as SPE, which is time consuming and has poor and inconsistent recoveries [5]. Thus, HPLC coupled with on-line SPE could offer several advantages, including reducing time and chemicals used, in addition to avoiding the common traditional problems associated with off-line SPE [7]. In addition, $[17,18]$ it has been reported that on-line SPE can be used to reach good LOQ levels in several analytical procedures. Therefore, this study aims to establish a simple but effective analytical method for determining five VAs (TC, OTC, SDZ, Norf, and Enorf) from swine manure matrix, depending on an on-line SPE technique coupled with UHPLC-DAD. In addition to this, choosing a suitable mobile phase and different solid extraction solutions were examined to achieve high recovery performance.

\section{Results}

\subsection{Optimization of the Chromatographic Conditions}

\subsubsection{Selection of the Optimum Detection Wavelength}

UHPLC with UV detectors are the most commonly used techniques for detecting Vas, due to their availability and convenient use in many labs. Diode array detectors (DAD) are more popular in use, since they have a wide UV spectrum (scanning range) covering a wide range of compounds. Here, in this study of the targeted VAs, each antibiotic has a certain wavelength range, for instance, wavelengths of $360 \mathrm{~nm}$ for TCs, $270 \mathrm{~nm}$ for SAs, and $280 \mathrm{~nm}$ for FQs. In this regard, a wide range of wavelengths was examined, including 230, 250, 251, 255, 260, 265, 267, 270, 273, 277, 280, 285, 290, 295, 320, 350, 355, 360, 365, and 370. Finally, 270 and $277 \mathrm{~nm}$ were found to be suitable by delivering high peak values for the targeted VAs (Table 1).

Table 1. The maximum UV-detection wavelengths and retention time of the five drugs.

\begin{tabular}{ccc}
\hline Antibiotic & Wavelength $\boldsymbol{\lambda}(\mathbf{n m})$ & Typical Retention Time (min) \\
\hline OTC & 270 & 9.14 \\
SDZ & 277 & 9.9 \\
Norf & 270 & 8.7 \\
Enorf & 277 & 10.2 \\
TC & 270 & 10.9 \\
\hline
\end{tabular}

\subsubsection{Selection of the Suitable Mobile Phase and Chromatographic Conditions}

Generally, in the reversed-phase column, antibiotics might easily show a tailing peak due to metal impurities or other residues [2]. Mobile phase acidity and reversed-phase column properties are responsible for peak quality. In order to avoid the formation of these peaks and adsorption of metal ions on the silanol group in the reversed column, a mobile 
phase containing various acids has been recommended [7]. Acids in the mobile phase act as a simple ionization suppression agent to minimize mixed separation mechanisms. The acids often used are formic acid and oxalic acid, which are able to sufficiently remove the effect of metal impurities and other residues on the stationary phase. Thus, oxalic acid was chosen in this study due to its ability to be used on wide ranges of VAs groups' separation through HPLC-UV. The mixture of ACN/oxalic acid/MeOH was previously recommended in the literature due to its ability to provide and improve the peak profiles. A mixture of ACN/oxalic acid was used in this study to separate targeted VAs from swine manure. Mobile phase $\mathrm{pH}$ content is of the most interest in light of the detection of analytes using HPLC, which is usually paired with the acid concentration. Thus, two $\mathrm{pH}$ levels (1.5 and 3.0) paired with two different concentrations of oxalic acid $(0.05 \mathrm{M}$ and $0.01 \mathrm{M})$ in the mobile phase were accomplished. The detection of targeted VAs under both mobile phases examined in this study is shown in Figures 1 and 2. The recovery of the targeted antibiotics used for comparison and assisting the mobile phase selection was observed, where the recovery of five VAs from both the liquid and solid fractions of swine manure was also observed. On average, $103 \%$ of the recovery of VAs was recorded in the liquid fraction, as opposed to $84.4 \%$ in the solid fraction with the mobile phase (1) (Figure 1), while an average recovery of $97.4 \%$ was obtained in liquid manure using the mobile phase $2(\mathrm{pH}$ 3.0) against an $86.5 \%$ average recovery in the solid fraction (Figure 2). The SDZ recorded the highest average recovery in liquid with both mobile phases, while OTC had the lowest average recovery. Since the difference between both mobile phases is not large, the selection could be due to other findings. At a low $\mathrm{pH}$, the efficiency of the separation of VAs is a little higher; however, this low $\mathrm{pH}$ could create many problems for the HPLC machine. When the $\mathrm{pH}$ was 1.5 , the system's valves and transition lines were blocked during the operation running, which (although unlikely) could have affected the detection performance with time. Thus, in light of this finding, mobile phase (2) (pH 3.0) is recommended to avoid this issue and keep the machine stable.

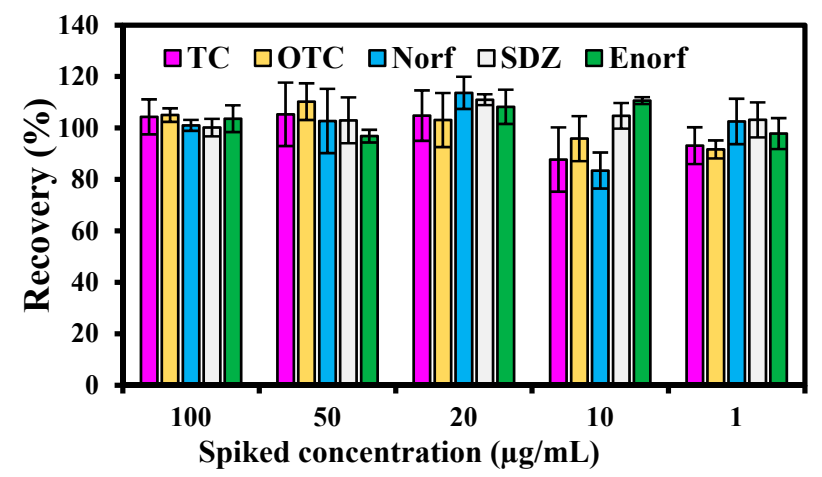

(A)

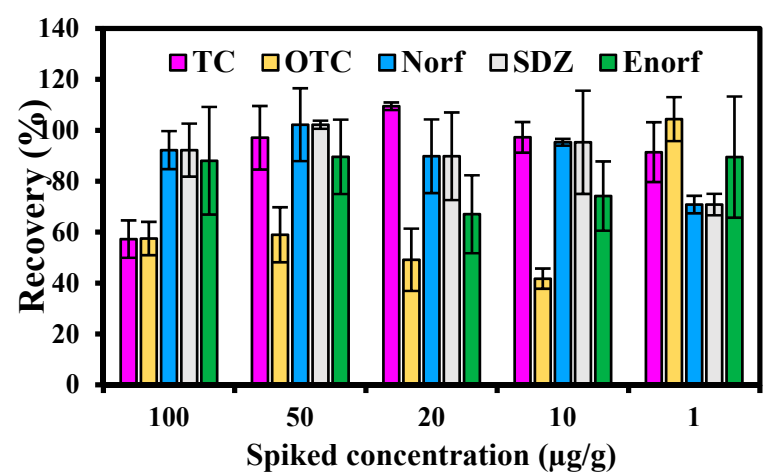

(B)

Figure 1. VAs recovery in liquid fraction (A) and solid fraction (B) at $\mathrm{pH} 1.5$, mobile phase (1).

Additionally, the ratio between the selected organic solvents, ACN and oxalic acid, was suggested and examined to optimize the mobile phase operation. In this regard, a gradient elution condition was followed, the retention time of five VAs extended, and the peak width satisfied. The mobile phase compositions for both HPLC-UV and on-line SPE are illustrated in Table 2. Thus, good separation was achieved by UHPLC-UV combined with on-line SPE. For UHPLC-UV, a composition of 40:60 ACN/Oxalic acid (0.01 M) was used after many trials. A retention time of $35 \mathrm{~min}$ was applied for all antibiotics together in the same run, including $5 \mathrm{~min}$ with $100 \%$ of $\mathrm{MeOH}$ for washing. A 5:95 gradient elution condition was used for on-line SPE until $10 \mathrm{~min}$ had elapsed, then switched to 80:20 until $20 \mathrm{~min}$, then returned to $5: 95$ until $30 \mathrm{~min}$ and $5 \mathrm{~min}$ with $100 \% \mathrm{MeOH}$ for washing. 


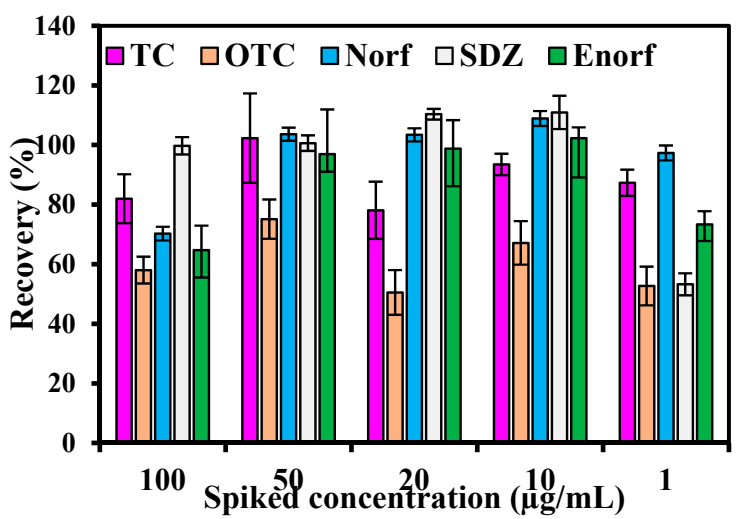

(A)

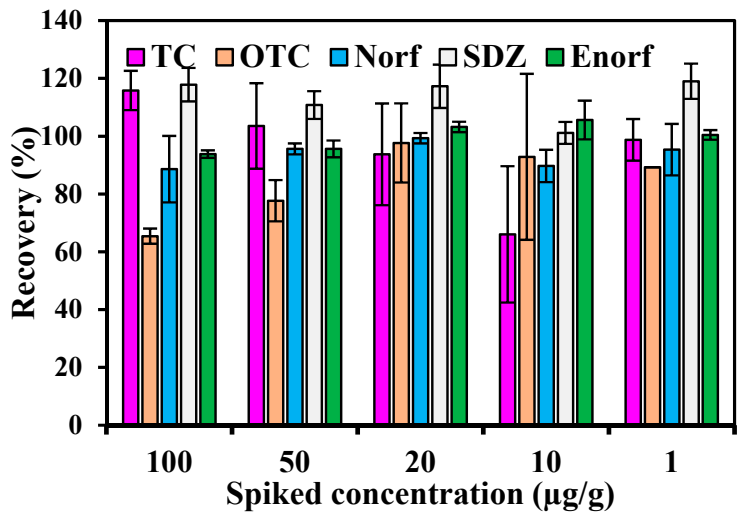

(B)

Figure 2. VAs recovery in liquid fraction (A) and solid fraction (B) at $\mathrm{pH} 3.0$, mobile phase (2).

Table 2. Instrument conditions of UHPLC combined with on-line SPE for analyzing five VAs.

\begin{tabular}{|c|c|c|c|c|c|c|c|c|c|}
\hline \multicolumn{2}{|c|}{ Mobile Phase } & \multicolumn{8}{|c|}{$\begin{array}{c}\text { Methanol (A) } \\
\text { Acetonitrile (B) } \\
0.05 \text { and 0.01 M Oxalic Acid in Highly Purified Distilled Water (C) }\end{array}$} \\
\hline \multicolumn{10}{|c|}{ Chromatography Condition } \\
\hline \multicolumn{5}{|c|}{ HPLC } & \multicolumn{5}{|c|}{ On-Line SPE } \\
\hline Time (min) & $\begin{array}{l}\text { Flow Rate } \\
\left(\mathrm{mL} \cdot \mathrm{min}^{-1}\right)\end{array}$ & $\mathrm{A}(\%)$ & B (\%) & $\mathrm{C}(\%)$ & Time (min) & $\begin{array}{l}\text { Flow Rate } \\
\left(\mathrm{mL} \cdot \mathrm{min}^{-1}\right)\end{array}$ & $\mathrm{A}(\%)$ & $\mathrm{B}(\%)$ & $\mathrm{C}(\%)$ \\
\hline 0 & \multirow{6}{*}{0.8} & 0 & 40 & 60 & 0 & \multirow{6}{*}{0.8} & 0 & 5 & 95 \\
\hline 10 & & 0 & 40 & 60 & 15 & & 0 & 5 & 95 \\
\hline 20 & & 0 & 60 & 40 & 20 & & 0 & 80 & 20 \\
\hline 25 & & 0 & 40 & 60 & 25 & & 0 & 5 & 95 \\
\hline 30 & & 0 & 40 & 60 & 30 & & 0 & 5 & 95 \\
\hline 35 & & 100 & 0 & 0 & 35 & & 100 & 0 & 0 \\
\hline
\end{tabular}

\subsection{Optimization of SPE}

\subsubsection{The Choice of On-Line SPE Column Sorbent}

SPE is commonly used to clean up samples due to its carbon backbone, aromatic region, and varied functional groups. Direct desorption of analytes from the pre-concentration column to the HPLC column by an optimal eluent for chromatographic separation is important. On-line SPE coupled with HPLC offers a fast and robust method for antibiotics detection. In this study, on-line SPE was applied to clean up the targeted VAs, which represent different classes and have different functional groups that make the detection process difficult. In this regard, to match the sorbent of VAs with analytical column C18, three different extraction solutions in solid fractions were used and evaluated.

\subsubsection{Optimal Extraction Sorbent for VAs in Solid Fraction}

Three different extraction solutions were investigated to extract five combined antibiotics from the solid fraction of swine manure (Table 3). There is a significant difference $(p<0.05)$ among the three extraction solution efficiencies. The results show that the T3 method, with an average recovery of $97.36 \%$, depicted a better recovery compared to $\mathrm{T} 1$ $(24.4 \%)$ and T2 (67.67\%). Both T2 and T3 are acceptable compared to the literature, due to both having a $\mathrm{Na}_{2}$ EDTA-McIlvaine buffer, which makes the system operate smoothly and gives a stable recovery. Li et al. [7] mentioned that using the same sorbent of the analytical separation column is considered an advantage and shows a good result. In addition, the targeted VAs in this study are known for their high potential separation performance through C18 column. Karci and Balcioglu [16] reported that $67 \%$ was an average recovery 
of eight VAs from manure using the T3 method. Moreover, an average recovery of five TCs compounds from honey was up to $95.2 \%$, using T3 methods at $\mathrm{pH} 4.0$ using on-line SPE as reported by [7]. Thus, the result showed a higher recovery with the optimized mobile phase than the literature. This could be attributed to the use of an on-line SPE technique combined with UHPLC-DAD.

Table 3. Comparison between three different solid extraction methods of 5 combined antibiotics recovery from swine manure.

\begin{tabular}{cccccc}
\hline \multirow{2}{*}{ Solid Extraction Solution } & \multicolumn{5}{c}{ Recovery (\%) } \\
\cline { 2 - 6 } & TC & OTC & SDZ & Enorf & Norf \\
\hline T1 & $84.5 \%$ & $2.85 \%$ & $11.37 \%$ & $1.43 \%$ & $21.87 \%$ \\
T2 & $77.2 \%$ & $67.15 \%$ & $80.63 \%$ & $62.11 \%$ & $51.28 \%$ \\
T3 & $95.58 \%$ & $84.58 \%$ & $113.2 \%$ & $99.73 \%$ & $93.71 \%$ \\
\hline
\end{tabular}

\subsection{The Suggested Method}

From the aforementioned discussion, it could be suggested that a UHPLC method with diode array detector (DAD) could be combined with on-line SPE and set at wavelengths of 270 and $277 \mathrm{~nm}$ for determining five spiked VAs (TC, OTC, Norf, SDZ, and Enorf) from swine manure. The suggested method involves the selection of a suitable mobile phase that contains a mixture of ACN/0.1 M oxalic acid in a gradient elution mode $(\mathrm{pH}$ at 3.0), followed by a pre-treatment method for solid fraction samples using $4 \mathrm{~mL}$ of an extraction solution containing a mixture between Mcllvaine buffer, 0.1 M Na2EDTA solution, and $\mathrm{MeOH}$ at a ratio of 25:25:50 (v/v/v). The separation step in the suggested method was achieved using a C18 reverse-phase column (AcclaimTM 120, $4.5 \times 250 \mathrm{~mm}$, $5 \mu \mathrm{m}$ particle size), with a column temperature of $30^{\circ} \mathrm{C}, 35 \mathrm{~min}$ as a total run time and injection volume of $50 \mu \mathrm{L}$, and an operation flow rate of $0.8 \mathrm{~mL} \mathrm{~min}^{-1}$. By applying the suggested method to blank and spiked samples, optimum chromatograms were obtained (Figure 3), indicating that extraction, clean up, and separation steps are satisfactory to remove the interference of endogenous compounds. However, because the described method has been applied to swine manure that is not treated with the selected antibacterial, investigating this method in swine manure containing excreted antibiotics from animals could give different results. Therefore, the validation of the suggested method was assessed and is stated in the following sections.

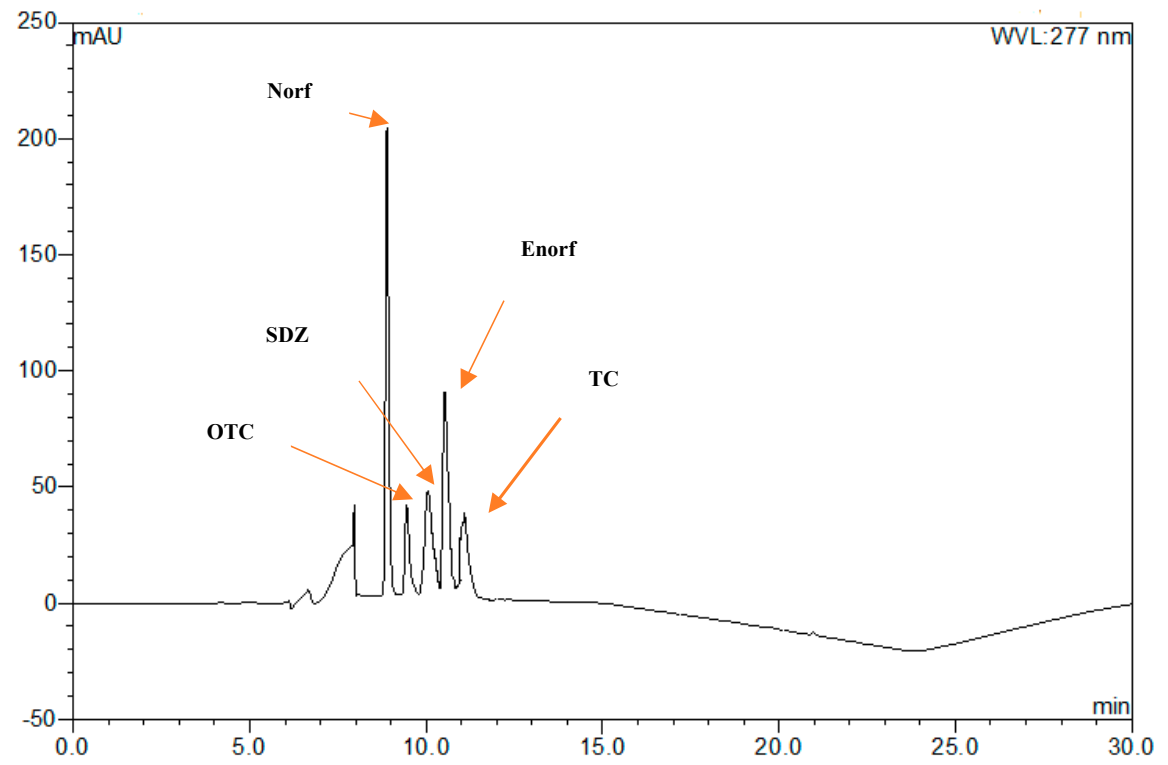

Figure 3. Chromatogram of five VAs $(10 \mu \mathrm{g} / \mathrm{mL})$ in swine manure; retention time $=8.7,9.14,9.8$, 10.3, and 10.9 minutes, respectively, of Norf, OTC, SDZ, Enorf, and TC at wavelength of $277 \mathrm{~nm}$. 


\subsection{Method Validation}

The suggested method was validated by evaluating the following parameters: specificity, calibration curve, sensitivity, and within-day and between-day precisions.

\subsubsection{Linearity of the Suggested Method}

The study was extended to assay the validation of the suggested method, where the obtained result regarding the linearity is shown in Table 4 . The linearity was evaluated by generating a calibration curve of 1 to $100 \mu \mathrm{g} \mathrm{mL}^{-1}$ for each compound mixed together at six points in triplicate. Obviously, the DAD response was found to be linear and highly correlated with the injected amount of combined VAs in both the liquid and solid fraction, where the calculated coefficient $\left(R^{2}\right)$ ranged from 0.995 to 0.999 in the liquid and from 0.991 to 0.999 in the solid fraction. Moreover, the sensitivity (the change in analytical signal units per $\mu \mathrm{m}$ VAs) of the suggested method found to be high, which is usually represented by the slope of the calibration curve [2]. The suggested model linearity of TC, OTC, Norf, SDZ, and Enorf for liquid and solid fractions is shown in Table 4.

Table 4. Linearity of the suggested method.

\begin{tabular}{ccccccc}
\hline \multirow{2}{*}{ Antibiotics } & \multicolumn{2}{c}{ Slope } & \multicolumn{2}{c}{ Intercept } & \multicolumn{2}{c}{$\mathbf{R}^{\mathbf{2}}$} \\
\cline { 2 - 7 } & Liquid & Solid & Liquid & Solid & Liquid & Solid \\
\hline TC & 1.07 & 1.514 & -0.51 & -6.62 & 0.995 & 0.994 \\
OTC & 0.795 & 0.825 & 0.05 & 5.486 & 0.997 & 0.992 \\
Norf & 2.34 & 2.85 & 3.62 & 5.27 & 0.999 & 0.994 \\
SDZ & 1.43 & 1.62 & 0.19 & 5.68 & 0.999 & 0.991 \\
Enorf & 2.17 & 3.17 & 1.73 & 2.18 & 0.999 & 0.999 \\
\hline
\end{tabular}

\subsubsection{Limit of Detection (LOD) and Limit of Quantification (LOQ)}

The limit of detection (LOD) is defined as the quantity yielding a detector response approximately equal to thrice the background noise and calculated by the standard deviation of the response $(\sigma)$ and the slope of the calibration curves $[5,14,15]$. The limit of quantitation (LOQ) is the lowest amount that can be analyzed within acceptable precision and accuracy at a signal to noise ratio of 10 [19]. In this study, LOD and LOQ were measured, and the obtained data are shown in Table 5. It was observed that the LOD of the suggested method ranged from 0.1 to $0.42 \mu \mathrm{g} \mathrm{mL}^{-1}$ in the liquid fraction and from 0.032 to $0.58 \mu \mathrm{g} \mathrm{g}^{-1} \mathrm{dw}$ in the solid fraction, while $\mathrm{LOQ}$ values ranged from 0.32 to $1.27 \mu \mathrm{g} \mathrm{mL} \mathrm{m}^{-1}$ in the liquid fraction and from 0.096 to $1.77 \mu \mathrm{g} \mathrm{g}^{-1} \mathrm{dw}$ in the solid fraction.

\subsubsection{Precision and Accuracy}

Precision is a measure of the results' variability from the system; commonly, it is described by the within-day and between-day relative standard deviation (RSD\%) of a set of replicated results [2]. As shown in Table 4, the within-day precision was calculated over a continuous 4 days by analyzing spiked samples in both matrix fractions, where RSD (\%) ranged from 0.29 to $17.85 \%$ in the liquid fraction and from 0.44 to $19.48 \%$ in the solid fraction, while the between-day precision was found to be in the range of 0.15 to $12.65 \%$ in the liquid and 0.44 to $19.8 \%$ in the solid fraction. The precision values are in accordance with the European Union regulation 2002/657/EC [20]. 
Table 5. Limits of detection ( $3 \sigma)$, limits of quantification $(10 \sigma)$, standard added recoveries, and relative standard deviations (RSDs, $n=6$ ) for the developed method.

\begin{tabular}{|c|c|c|c|c|c|c|c|c|c|}
\hline \multirow[b]{2}{*}{ Compound } & \multirow{2}{*}{$\begin{array}{c}\text { Spiked } \\
\text { Level } \\
\left(\mu \mathrm{g} \cdot \mathrm{g}^{-1}\right)\end{array}$} & \multicolumn{2}{|c|}{ LOD } & \multicolumn{2}{|c|}{ LOQ } & \multicolumn{2}{|c|}{ Within-Day RSD (\%) } & \multicolumn{2}{|c|}{ Between-Day RSD (\%) } \\
\hline & & $\begin{array}{l}\text { Liquid ( } \mu \mathrm{g} \\
\left.\mathrm{mL}^{-1}\right)\end{array}$ & $\begin{array}{c}\text { Solid } \\
\left(\mu \mathrm{g} \cdot \mathrm{g}^{-1}\right)\end{array}$ & $\begin{array}{l}\text { Liquid ( } \mu \mathrm{g} \\
\left.\mathrm{mL}^{-1}\right)\end{array}$ & $\begin{array}{c}\text { Solid } \\
\left(\mu \mathrm{g} \cdot \mathrm{g}^{-1}\right)\end{array}$ & Liquid & Solid & Liquid & Solid \\
\hline \multirow{5}{*}{$\mathrm{TC}$} & 1 & \multirow{5}{*}{0.15} & \multirow{5}{*}{0.29} & \multirow{5}{*}{0.47} & \multirow{5}{*}{0.89} & 11.27 & 1.63 & 9.20 & 10.58 \\
\hline & 10 & & & & & 6.97 & 4.59 & 9.02 & 19.48 \\
\hline & 20 & & & & & 8.24 & 16.94 & 4.25 & 9.01 \\
\hline & 50 & & & & & 16.9 & 15.17 & 3.40 & 2.26 \\
\hline & 100 & & & & & 16.58 & 14.87 & 5.87 & 0.82 \\
\hline \multirow{5}{*}{ OTC } & 1 & \multirow{5}{*}{0.1} & \multirow{5}{*}{0.58} & \multirow{5}{*}{0.32} & \multirow{5}{*}{1.77} & 15.52 & 7.14 & 6.57 & 3.65 \\
\hline & 10 & & & & & 11.00 & 17.3 & 5.24 & 10.51 \\
\hline & 20 & & & & & 1.59 & 13.67 & 0.8 & 12.92 \\
\hline & 50 & & & & & 10.87 & 12.69 & 11.34 & 17.45 \\
\hline & 100 & & & & & 13.78 & 7.49 & 8.21 & 3.67 \\
\hline \multirow{5}{*}{ Norf } & 1 & \multirow{5}{*}{0.42} & \multirow{5}{*}{0.032} & \multirow{5}{*}{1.27} & \multirow{5}{*}{0.096} & 17.78 & 9.94 & 8.39 & 5.56 \\
\hline & 10 & & & & & 9.28 & 13.17 & 2.81 & 9.17 \\
\hline & 20 & & & & & 4.68 & 10.32 & 2.30 & 9.48 \\
\hline & 50 & & & & & 5.5 & 17.22 & 4.80 & 18.06 \\
\hline & 100 & & & & & 17.85 & 10.69 & 12.65 & 5.15 \\
\hline \multirow{5}{*}{ SDZ } & 1 & \multirow{5}{*}{0.34} & \multirow{5}{*}{0.13} & \multirow{5}{*}{1.04} & \multirow{5}{*}{0.39} & 1.36 & 8.68 & 4.47 & 10.65 \\
\hline & 10 & & & & & 5.61 & 13.73 & 8.21 & 0.8 \\
\hline & 20 & & & & & 2.15 & 10.79 & 1.09 & 17.28 \\
\hline & 50 & & & & & 15.52 & 1.59 & 2.86 & 7.22 \\
\hline & 100 & & & & & 9.16 & 19.8 & 0.68 & 4.48 \\
\hline \multirow{5}{*}{ Enorf } & 1 & \multirow{5}{*}{0.26} & \multirow{5}{*}{0.05} & \multirow{5}{*}{0.79} & \multirow{5}{*}{0.16} & 7.03 & 16.93 & 2.13 & 12.02 \\
\hline & 10 & & & & & 5.37 & 19.07 & 6.08 & 0.44 \\
\hline & 20 & & & & & 0.29 & 6.02 & 0.15 & 3.08 \\
\hline & 50 & & & & & 12.69 & 0.87 & 2.74 & 10.23 \\
\hline & 100 & & & & & 4.32 & 12.15 & 3.43 & 16.24 \\
\hline
\end{tabular}

\section{Materials and Methods}

\subsection{Reagents and Materials}

Standards of five veterinary antibiotics (VAs) (Figure 3) (Tetracycline (TC, 90\%), Oxytetracycline (OTC, 98\%), Sulfadiazine (SDZ, 98\%), Norfloxacin (Norf, 98\%), Enrofloxacin (Enorf, 98\%)) were purchased from Sigma-Aldrich (St. Louis, MO, US) (CAS Reg. No. 6054-8 for TC, CAS Reg. No. 6153-64-6 for OTC, CAS Reg. No. 68-35-9 for SDZ, CAS Reg. No. 70458-96-7 for Norf, and CAS Reg. No. 93106-60-6 for Enorf) (the structures are presented in Figure 4). Acetonitrile (ACN) and methanol $(\mathrm{MeOH})$ of HPLC grade were purchased from Sigma-Aldrich. Oxalic acid, disodium ethylene-diaminetetraacetat $\left(\mathrm{Na}_{2} \mathrm{EDTA}\right)$, disodium hydrogen phosphate $\left(\mathrm{Na}_{2} \mathrm{HPO}_{4}\right)$, and sodium dihydrogen phosphate $\left(\mathrm{NaH}_{2} \mathrm{PO}_{4}\right)$ of analytical-reagent grade were obtained from Beijing Chemicals Company (Beijing, China). Deionized water (Milli-QMillipore, Bedford, MA, USA) was used in the study.

\subsection{Apparatus}

An Ultra-High-Performance-Liquid Chromatography (UHPLC) system-Ultimate 3000 Diod Array Detector (DAD) using a Thermo Scientific Dionex Ultimate 3000 system (Thermo Scientific Fisher, DIONEX, Sunnyvale, CA, US) was used, coupled with a thermostatic auto-sampler and an on-line SPE system (Dionex IonPacTM NG1, Guard $\times 35 \mathrm{~mm}$, CA 94085, US). A C18 reverse-phase column (AcclaimTM 120, $4.5 \times 250 \mathrm{~mm}$, $5 \mu \mathrm{m}$ particle size, Thermo fisher, Sunnyvale, CA, US) was used. The $\mathrm{pH}$ meter, ultrasonic bath (Buhler, Leinfelden-Echterdingen, Germany), and freeze-dried machine were also used for sample preparation. 
<smiles>CN(C)C1C(O)=C(C(N)=O)C(=O)C(O)(O)C2(C)C(O)=C3C(=O)c4c(O)cccc4C(C)(O)C3CC12C</smiles>

Tetracycline

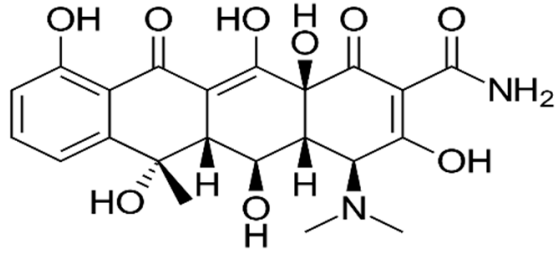

Oxytetracycline<smiles>Nc1ccc(S(=O)(=O)Nc2ncccn2)cc1</smiles>

Sulfadiazine<smiles>CCn1cc(C(=O)O)c(=O)c2cc(F)c(N3CCNCC3)cc21</smiles>

Norfloxacin<smiles>CCN1CCN(c2cc3c(cc2F)C(=O)C(C(=O)O)=CC3N2CC2)CC1</smiles>

\section{Enrofloxacin}

Figure 4. Chemical structure of Tetracycline, Oxytetracycline, Sulfadiazine, Norfloxacin, and Enrofloxacin.

\subsection{Standard Solutions}

Stock standard solutions of each compound of TC, OTC, SDZ, Norf, and Enorf were prepared by dissolving $100 \mathrm{mg}$ of the compound in $100 \mathrm{~mL}$ of methanol to obtain a final concentration of $1.0 \mathrm{mg} \mathrm{mL}^{-1}$. Stock standard solutions were put in amber glass to prevent photo-degradation and stored at $-20^{\circ} \mathrm{C}$ and were stable for at least 4 weeks [2,3,5-7]. A working mixed-standard solution $\left(100 \mu \mathrm{g} \mathrm{mL}^{-1}\right)$ was diluted using the mobile phase to give a series of dilutions $\left(100,50,20,10,1,0.5\right.$ and $\left.0.2 \mu \mathrm{g} \mathrm{mL}^{-1}\right)$, and it was stable for at least one week when stored at $4{ }^{\circ} \mathrm{C}$ in a refrigerator.

\subsection{Sample Preparation}

Liquid samples: swine liquid manure (5\% total solids (TS)) samples were centrifuged at 10,000 rpm for $10 \mathrm{~min}$ at $4{ }^{\circ} \mathrm{C}$ with a high-speed refrigerated centrifuge (TGL-16 M, Shanghai, China), then the supernatant was filtered through a $0.45 \mu$ filter, and then a $0.22 \mu$ filter. Then samples $\mathrm{pH}$ was adjusted to 3.0 by adding $\mathrm{H}_{3} \mathrm{PO}_{4}$ before UHPLC injection step (Figure 5). 


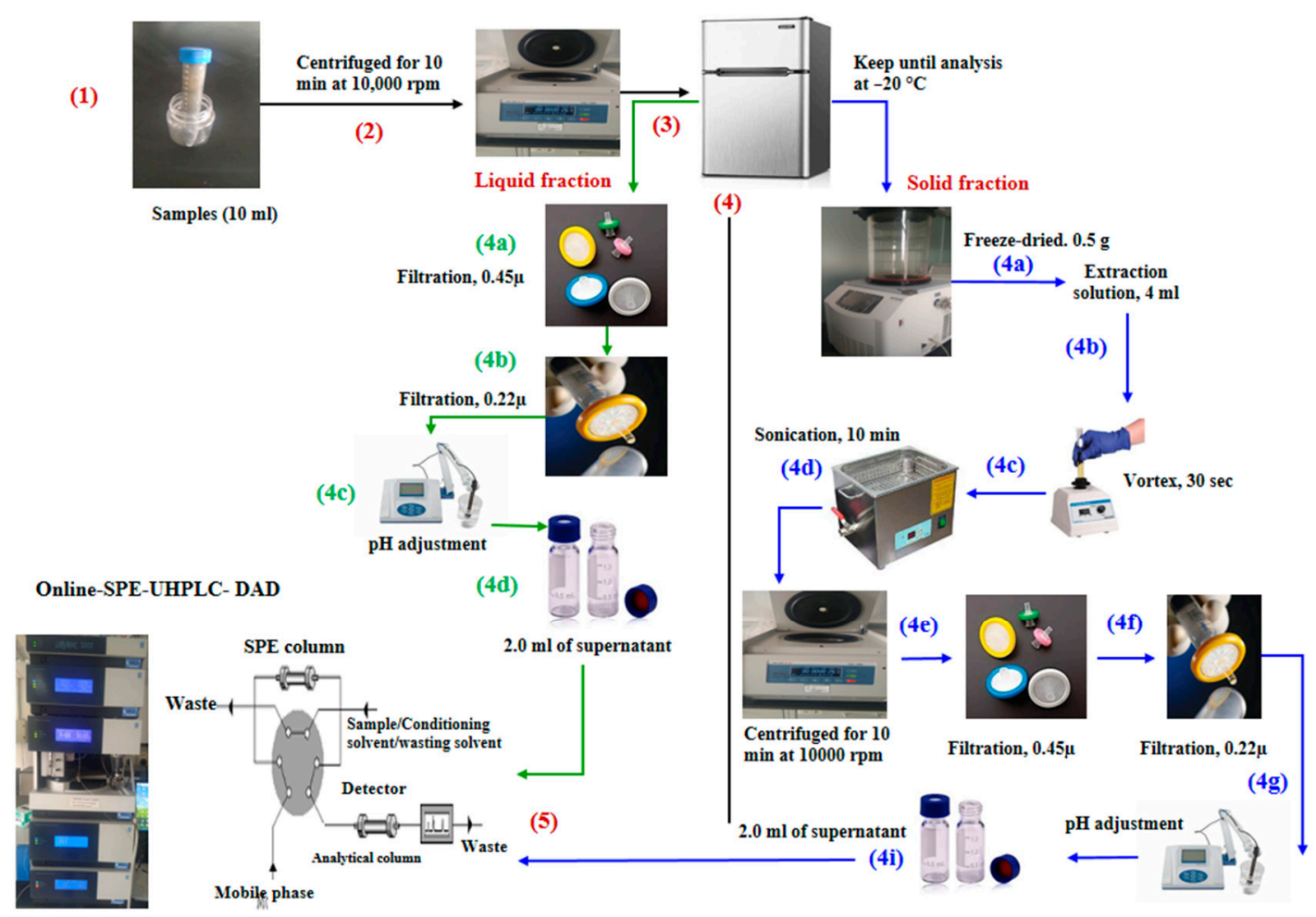

Figure 5. Scheme for the determination of targeted antibiotic residues in swine manure.

Solid samples: $0.5 \mathrm{~g}$ of freeze-dried and ground samples were measured and spiked with standard solutions as reported by Marti et al. [21]. Solid samples were extracted by passing through three different solid extraction solutions, where samples were transferred into a centrifuge tube and $4 \mathrm{~mL}$ of extraction buffer was added as follows:

i. $\quad(\mathrm{T} 1)$ : a mixture (50:50 v/v) of $\mathrm{MeOH} / \mathrm{ACN}$ and $\mathrm{pH}$ adjusted to 3.0;

ii. (T2): saturated aqueous $\mathrm{Na}_{2}$ EDTA, water, and $\mathrm{Na}_{2}$ EDTA-Mcllvaine buffer ( $\mathrm{pH} 4.0$ ) as developed by Li et al. [7];

iii. (T3): a mixture between a McIlvaine buffer ( $0.1 \mathrm{M} \mathrm{Na}_{2}$ EDTA) solution, and $\mathrm{MeOH}$ at a ratio of 25:25:50 (based on the volume $v / v / v$ ), and $\mathrm{pH}$ was adjusted to 7.2 by adding $6 \mathrm{~N} \mathrm{NaOH}$ solution. The Mcllvaine buffer was prepared by mixing $0.2 \mathrm{M}$ citric acid and 0.4 $\mathrm{M} \mathrm{Na}_{2} \mathrm{HPO}_{4}$ solutions at a ratio of (90:60) (based on the volume $\left.v / v\right)$ ) as reported by Karci and Balcioglu [16]. The samples' pH was adjusted to 3.0 before HPLC injection.

Generally, after adding extraction solution, the samples were vortexed for $30 \mathrm{~s}$ and then sonicated using an ultrasonic bath (Buhler, Leinfelden-Echterdingen, Germany) for $10 \mathrm{~min}$, then centrifuged at 10,000 rpm for $10 \mathrm{~min}$ at $4{ }^{\circ} \mathrm{C}$. The supernatant was filtered through a $0.45 \mu \mathrm{m}$ filter, and then a $0.22 \mu \mathrm{m}$ filter. The $\mathrm{pH}$ was adjusted to 3.0 by adding $\mathrm{H}_{3} \mathrm{PO}_{4}$.

\subsection{Cleaning $U p$}

The supernatant was filtered and loaded onto an on-line SPE in an HPLC machine directly.

\subsection{Chromatographic Separation}

Two different mobile phases were finally used after several trials to obtain the best mobile phase mixture for the targeted VAs detection. The first mobile phase consisted of methanol (A), acetonitrile (B), and $0.05 \mathrm{M}$ oxalic acid, as recommended by Abbasi et al. [22], while the second mobile phase was acetonitrile (B), 0.01M oxalic acid (C), and methanol (A) for washing only (Table 2). The prepared mobile phase was filtered through a $0.45 \mu$ filter and then degassed through sonication for $10 \mathrm{~min}$ before application. Detection was 
carried out at $260 \mathrm{~nm}$ for TC, $270 \mathrm{~nm}$ for Norf and Enorf, and $277 \mathrm{~nm}$ for SDZ and OTC. The on-line SPE system was used. A C18 reverse-phase column was used at $30{ }^{\circ} \mathrm{C}$ with $35 \mathrm{~min}$ as a total run time and an injection volume of $50 \mu \mathrm{L}$, with a flow rate of $0.8 \mathrm{~mL} \mathrm{~min}{ }^{-1}$. The software used for control and data acquisition was Dionex ${ }^{\mathrm{TM}}$ Chromeleon $^{\mathrm{TM}} 6.8$ (Thermo Fisher Scientific, Sunnyvale, CA, US). External calibration curves were constructed by preparing the standard solutions at six known concentrations $\left(0.5-100 \mu \mathrm{g} \mathrm{mL}^{-1}\right.$ for all VAs). The analytes' concentration in the sample matrices was determined using peak areas that corresponded to the unknown concentrations in the calibration curve.

\subsection{Assay Validation}

In order to confirm the suitability of the method, it was validated for specificity, linearity, precision, accuracy, limit of quantification (LOQ), limit of detection (LOD), and stability.

\subsubsection{Specificity, Linearity, Limit of Detection (LOD), and Limit of Quantification (LOQ)}

The validation of specificity, linearity, limit of detection (LOD), limit of quantification (LOQ), recovery yield, and precision for the method was determined. A selected number of swine animals from the National Changping Integrated Agricultural Engineering Technology Center, Livestock and Poultry Branch, Beijing, China were non-medicated. Pig manure was sampled directly from the central pit located at the College of Engineering, China Agricultural University, Beijing, China, sealed well, and stored in a cold, dark room at $4{ }^{\circ} \mathrm{C}$ until utilization. Blank samples and spiked samples at 100,50,20, 10, 1, 0.5, and $0.2 \mu \mathrm{g} \mathrm{mL}^{-1}$ for both liquid and solid fractions were analyzed on different days, covering all operation conditions. The sample preparation and chromatographic conditions were optimized to guarantee that there were no matrix effects within the retention time of the tested compounds. The response for each antibiotic detected with the HPLC methods was evaluated for linearity, and the limits of detection and quantification for the instrument (LOD and LOQ) were determined, using calibration curves containing six concentration levels $(0.5,1,10,20,50$, and $100 \mathrm{mg} / \mathrm{L})$. LOD and LOQ were determined using the standard deviation of the response $(\sigma)$ and the slope of the calibration curves (S) [23] as follows:

$$
\begin{aligned}
& \mathrm{LOD}=(3.3 \sigma) / \mathrm{S} \\
& \mathrm{LOQ}=(10 \sigma) / \mathrm{S}
\end{aligned}
$$

\subsubsection{Precision}

Precision was evaluated by measuring intra-and inter-assay relative RSD\%. The intraassay (within-day) precision was performed by measuring targeted antibiotics in one day. The inter-assay (between-day) precision was determined by analyzing each calibration sample once for 4 consecutive days. Within-day assay and between-day assay precision were expressed as the percentage relative standard deviation (RSD).

\subsubsection{Accuracy}

Accuracy was expressed as the percentage recovery and calculated as the measured/theoretical value $\times 100$. VAs' recovery was tested in triplicate for five concentrations $\left(100,50,20,10\right.$, and $\left.1 \mu \mathrm{g} \mathrm{mL}^{-1}\right)$.

$$
\text { Recovery }(\%)=(\mathrm{C} 1-\mathrm{C} 2) / \mathrm{C} 3 \times 100
$$

In which $\mathrm{C} 1$ = concentration of analyte in the fortified sample, $\mathrm{C} 2$ = concentration of analyte in the non-fortified sample, and C3 = concentration of analyte added to the fortified sample. 


\section{Conclusions}

A convenient analytical method using the Ultra-High-Performance Liquid Chromatography method with diode array detection (UHPLC-DAD) coupled with on-line SPE was developed and validated to determine five different veterinary antibiotics (VAs) residues simultaneously in swine manure. Among a wide range of wavelengths, 270 and $277 \mathrm{~nm}$ resulted in high peaks. The mobile phase with $\mathrm{pH} 1.5$ performed well; however, the mobile phase (2) with $\mathrm{pH} 3.0$ was recommended due to HPLC stability and performance. Moreover, an optimized solid extraction buffer solution (T3) of VAs from swine manure showed a high extraction efficiency of over $97 \%$. The LOD and LOQ values paired with this method were higher in the liquid fraction than in the solid fraction. The developed method was selective, robust, simple, fast, and inexpensive, and it could be a methodological tool for laboratories dedicated to analyzing emerging pollutants that do not have mass spectrometry detectors.

Author Contributions: M.S.G.: Conceptualization, Methodology, Investigation, Writing—original draft. Funding acquisition, X.L.: Validation, Resources. Z.Z.: Writing-review and editing, Conceptualization. A.A.-A.: Validation, Resources. H.S.: Validation, Resources. M.A.G.: Formal analysis, Visualization. M.S.: Formal analysis, Visualization. M.P.: Formal analysis, Visualization. J.G.: Writing — review and editing, Supervision. R.D.: Funding acquisition. All authors have read and agreed to the published version of the manuscript.

Funding: This work was jointly supported by the funding of the National Natural Science Foundation of China (Grant No. U20A2086) and the China National Key Research and Development Plan Project (Grant No. 2018YFD0800100).

Institutional Review Board Statement: This work does not include human or animal samples.

Informed Consent Statement: This work does not include human or animal samples.

Data Availability Statement: Data and all relevant information are available from the authors via email at: jianbinguo@cau.edu.cn (Jianbin Guo) and saadga22@gmail.com (M.S. Gaballah).

Conflicts of Interest: All authors declare that they have no conflict of interest.

\section{References}

1. Gaballah, M.S.; Guo, J.; Sun, H.; Aboagye, D.; Sobhi, M.; Muhmood, A.; Dong, R. A review targeting veterinary antibiotics removal from livestock manure management systems and future outlook. Bioresour. Technol. 2021, 333, 125069. [CrossRef]

2. Shalaby, A.R.; Salama, N.A.; Abou-Raya, S.H.; Emam, W.H.; Mehaya, F.M. Validation of HPLC method for determination of tetracycline residues in chicken meat and liver. Food Chem. 2011, 124, 1660-1666. [CrossRef]

3. Spielmeyer, A. Occurrence and fate of antibiotics in manure during manure treatments: A short review. Sustain. Chem. Pharm. 2018, 9, 76-86. [CrossRef]

4. Rufino, M.C.; Brandt, P.; Herrero, M. Reducing uncertainty in nitrogen budgets for African livestock systems. Environ. Res. Lett. Pap. 2014, 9, 105008. [CrossRef]

5. Wang, R.; Wei, R.; Chen, M.; Wang, T. A new, simple and rapid HPLC method for determination of chlortetracycline in pig solid manure. Ital. J. Anim. Sci. 2010, 9, 190-194. [CrossRef]

6. Springer, V.; Jacksé, J.; Ek, P.; Lista, A.G.; Emmer, Å. Determination of fluoroquinolones in bovine milk samples using a pipette-tip SPE step based on multiwalled carbon nanotubes prior to CE separation. J. Sep. Sci. 2014, 37, 158-164. [CrossRef] [PubMed]

7. Li, J.; Chen, L.; Wang, X.; Jin, H.; Ding, L.; Zhang, K.; Zhang, H. Determination of tetracyclines residues in honey by on-line solid-phase extraction high-performance liquid chromatography. Talanta 2008, 75, 1245-1252. [CrossRef] [PubMed]

8. Yu, H.; Tao, Y.; Chen, D.; Wang, Y.; Yuan, Z. Development of an HPLC-UV method for the simultaneous determination of tetracyclines in muscle and liver of porcine, chicken and bovine with accelerated solvent extraction. Food Chem. 2011, 124, 1131-1138. [CrossRef]

9. Sartini, I.; Beata, Ł.-W.; Tae, W.K.; Andrzej, L.; Amnart, P.; Mario, G. Pharmacokinetics and tissue analysis of levofloxacin in sheep (Ovis aries Linnaeus) after multiple-dose administration. Res. Vet. Med. 2020, 128, 124-128.

10. Yu, H.; Mu, H.; Hu, Y.M. Determination of fluoroquinolones, sulfonamides, and tetracyclines multiresidues simultaneously in porcine tissue by MSPD and HPLC-DAD. J. Pharm. Anal. 2012, 2, 76-81. [CrossRef]

11. Kumar, A.; Panda, A.K.; Sharma, N. Determination of antibiotic residues in bovine milk by HPLC-DAD and assessment of human health risks in Northwestern Himalayan region, India. J. Food Sci. Technol. 2021, 1-10. [CrossRef]

12. Sartini, I.; Łebkowska-Wieruszewska, B.; Lisowski, A.; Poapolathep, A.; Giorgi, M. Danofloxacin pharmacokinetics and tissue residues in Bilgorajska geese. Res. Vet. Sci. 2021, 136, 11-17. [PubMed] 
13. Kumar, A.; Gill, J.P.S.; Bedi, J.S.; Chhuneja, P.K.; Kumar, A. Determination of antibiotic residues in Indian honeys and assessment of potential risks to consumers. J. Apic. Res. 2020, 59, 25-34. [CrossRef]

14. Sher, M.; Hussain, M.A.; Mehmood, M.H.; Hassan, M.N.; Bashir, S. Bioequivalence of norfloxacin by HPLC-UV method. J. Chil. Chem. Soc. 2010, 55, 203-205. [CrossRef]

15. Vella, J.; Busuttil, F.; Bartolo, N.S.; Sammut, C.; Ferrito, V.; Serracino-Inglott, A.; Azzopardi, L.M.; LaFerla, G. A simple HPLC-UV method for the determination of ciprofloxacin in human plasma. J. Chromatogr. B. 2015, 989, 80-85. [CrossRef] [PubMed]

16. Karci, A.; Balcioglu, I.A. Investigation of the tetracycline, sulfonamide, and fluoroquinolone antimicrobial compounds in animal manure and agricultural soils in Turkey. Sci. Total Environ. 2009, 407, 4652-4664. [CrossRef]

17. Barreca, S.; Busetto, M.; Colzani, L.; Clerici, L.; Daverio, D.; Dellavedova, P.; Balzamo, S.; Calabretta, E.; Ubaldi, V. Determination of estrogenic endocrine disruptors in water at sub-ng L-1 levels in compliance with Decision 2015/495/EU using offline-online solid phase extraction concentration coupled with high performance liquid chromatography-tandem mass spectrometry. Microchem. J. 2019, 147, 1186-1191. [CrossRef]

18. Barreca, S.; Busetto, M.; Vitelli, M.; Colzani, L.; Clerici, L.; Dellavedova, P. Development of a rapid and accurate method for the determination of key. J. Chem. 2018, 2018, 9. [CrossRef]

19. Orecchio, S.; Indelicato, R.; Barreca, S. Determination of selected phthalates by gas chromatography-mass spectrometry in personal perfumes. J. Toxicol. Environ. Health Part 2015, 114, 187-191. [CrossRef]

20. Commission Decision of 12 August 2002 implementing Council Directive 96/23/EC concerning the performance of analytical methods and the interpretation of results (2002/657/EC) (2002). Off. J. Eur. Commun. 2002, L221, 8-36.

21. Marti, E.; Gros, M.; Boy-roura, M.; Ovejero, J.; Busquets, A.M.; Colón, J.; Petrovic, M.; Ponsá, S. Pharmaceuticals removal in an on-farm pig slurry treatment plant based on solid-liquid separation and nitrification-denitrification systems. Waste Manag. 2020, 102, 412-419. [CrossRef] [PubMed]

22. Abbasi, M.M.; Nemati, M.; Babaeia, H.; Ansarin, M.; Nourdadgar, A.O.S. Solid-phase extraction and simultaneous determination of tetracycline residues in edible cattle tissues using an HPLC-FL method. Iran. J. Pharm. Res. 2012, 11, 781-787. [CrossRef]

23. Zhao, L.; Dong, Y.H.; Wang, H. Residues of veterinary antibiotics in manures from feedlot livestock in eight provinces of China. Sci. Total Environ. 2010, 408, 1069-1075. [CrossRef] [PubMed] 